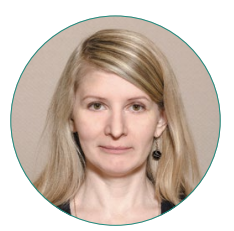

Н. С. Киреева

\title{
ПРЕДПОЧТЕНИЯ ПОЛЬЗОВАТЕЛЕЙ СЕРВИСОВ СОВМЕСТНОГО ПОЛЬЗОВАНИЯ (ШЕРИНГА) ВЕЩЕЙ: РЕЗУЛЬТАТЫ ИССЛЕДОВАНИЯ СТАТИСТИКИ ПОИСКОВЫХ ЗАПРОСОВ
}

\section{Правильная ссылка на статью:}

Киреева Н. С. Предпочтения пользователей сервисов совместного пользования (шеринга) вещей: результаты исследования статистики поисковых запросов // Мониторинг общественного мнения: экономические и социальные перемены. 2021. № 4. С. 258-274. https://doi.org/10.14515/monitoring.2021.4.1678.

\section{For citation:}

Kireeva N. S. (2021) Preferences of Sharing Services Users: A Study of Search Queries Statistics. Monitoring of Public Opinion: Economic and Social Changes. No. 4. P. 258-274. https:// doi.org/10.14515/monitoring.2021.4.1678. (In Russ.) 
ПРЕДПОЧТЕНИЯ ПОЛЬЗОВАТЕЛЕЙ СЕРВИСОВ СОВМЕСТНОГО ПОЛЬЗОВАНИЯ (ШЕРИНГА) ВЕЩЕЙ: РЕЗУЛЬТАТЫ ИССЛЕДОВАНИЯ СТАТИСТИКИ ПОИСКОВЫХ ЗАПРОСОВ

КИРЕEВА Наталья Сергеевна - кандидат экономических наук, доцент, кафедра предпринимательства и логистики, Российский экономический университет имени Г.В. Плеханова, Москва, Россия

E-MAIL: nskireeva@gmail.com

https://orcid.org/0000-0003-1008-7026

Аннотация. На основе анализа данных о поисковой активности, собранных с помощью инструментов Google Trends и "Яндекс. Подбор слов", в статье анализируются предпочтения российских пользователей сервисов шеринга вещей. Выявлены особенности их поискового интереса, представлены преимущества, получаемые обществом, владельцами и пользователями вещей от аренды товаров. Установлены ключевые мотивы посетителей сервисов шеринга вещей: бережливость и желание временно обладать более качественными и дорогостоящими предметами, чем они могут позволить себе купить. Исследование показало, что динамика популярности различных товаров у пользователей шеринга вещей неоднородна: например, быстрый рост спроса на квадроциклы и сноуборды в последние годы сменился снижением, а востребованность инструментов и платьев, наоборот, увеличилась. Основными препятствиями для развития аренды вещей выступают: ее высокая стоимость, низкая осведомленность потребителей, трудности с доставкой, большие затраты времени на поиск и получение товара,
PREFERENCES OF SHARING SERVICES USERS: A STUDY OF SEARCH QUERIES STATISTICS

Natalia S. KIREEVA ${ }^{1}$ - Cand. Sci. (Econ.), Associate Professor, Entrepreneurship and Logistics Department E-MAIL: nskireeva@gmail.com https://orcid.org/0000-0003-1008-7026

\footnotetext{
1 Plekhanov Russian University of Economics, Moscow, Russia
}

Abstract. The article analyzes preferences of Russian users of things sharing services basing on the analysis of search activity data collected using Google Trends and "Yandex. Word selection". The author reveals the main features of search interest and reviews the benefits for society, owners and users of things from the lease of goods. According to the study results, the users of the sharing services are mostly motivated by thrift and the desire to temporarily possess more expensive items of better quality than they can afford to buy. The study showed that the dynamics of the popularity of shared goods differs across categories. For example, the rapid growth in demand for ATVs and snowboards has reverted in recent years, while the demand for tools and dresses, on the contrary, has increased. The main obstacles to the development of the goods' rental are its high cost, low consumer awareness, difficulties in logistics, long time necessary for search and delivery, and possible risks of damage. The article concludes that, on the one hand, Russian consumers are gradually realizing the benefits of sharing things, while on the other hand, the number of visitors 
возможные риски его повреждения. В статье делается вывод, что, с одной стороны, российские потребители постепенно осознают преимущества шеринга вещей, а с другой - количество посетителей сайтов, предоставляющих услуги по аренде различных товаров, невелико и намного ниже, чем у сайтов торговых компаний. Таким образом, шеринг вещей, несмотря на быстрое развитие, пока не составляет заметную конкуренцию розничной торговле.

Ключевые слова: шеринговая экономика, шеринг вещей, предпочтения пользователей, Google Trends, поисковые запросы to sites that provide rental services for various goods is small and much lower than that of the sites of trading companies. Thus, the sharing of things, despite the rapid development, does not yet constitute a noticeable competition for the retail sector.

Keywords: sharing economy, sharing things, user preferences, Google Trends, search queries

\section{Введение}

Шеринговая экономика (sharing economy) - новая социально-экономическая модель, меняющая отношение к собственности и потреблению, основанная на коллективном использовании товаров и услуг, бартере и аренде вместо владения. Шеринговая экономика исходит из идеи, что иногда удобнее платить за временный доступ к продукту, чем постоянно обладать им [Botsman, Rogers, 2010].

Не существует единого конвенционально закрепленного определения этого понятия и его корректного перевода на русский язык. Встречаются как использование калькированного англицизма "шеринговая экономика", так и попытки дать соответствующий содержательный перевод данного термина: «экономика совместного потребления", "долевая экономика", "разделяемая экономика", "экономика по требованию", "экономика участия", "коллаборативная экономика", "экономика обмена" и т.д. Многообразие подходов обусловлено гетерогенностью реализуемых проектов по совместному пользованию (шерингу) имуществом [Маркеева, 2017].

Концепция коллективного пользования вещами не нова. Библиотеки, приобретающие и хранящие книги для читателей, существуют с древнейших времен. Однако развитие цифровых технологий в последнее десятилетие дало мощный толчок для распространения шеринга вещей. С появлением онлайн-платформ, мобильных устройств и электронных транзакций потребительские товары стали намного более доступны для временного пользования [Belk, 2014; Frenken, 2017].

Помимо цифровых технологий, популярности шеринга способствуют социальные (смена ценностей, кризис вертикального доверия), экономические (рост неравенства, сокращение имущества среднего класса) и экологические (рост популярности рециклинга) факторы [Земскова, 2019]. 
В результате в России, как и в мире в целом, объем шеринговой экономики быстро растет. Так, объем услуг, оказываемых населению предприятиями по прокату, в последние десять лет увеличился более чем в три раза: в 2019 г. этот показатель, по данным Росстата, составил 18,7 млрд рублей, что на 34 \% больше, чем в 2018 г., и в 3,1 раза больше, чем в 2010 г. ${ }^{1}$ По данным исследования, проведенного “ТИАРЦентром" и Российской ассоциацией электронных коммуникаций (РАЭК), объем транзакций Р2P 2 аренды вещей по итогам 2019 г. составил около 220 млн руб. и показал рост в 22 \% по сравнению с 2018 г., и $275 \%$ - по сравнению с 2017 г. $^{3}$ Шеринг вещей может принести обществу экологическую и экономическую выгоду за счет удовлетворения потребностей населения с использованием меньшего количества товаров [Tukker, 2015; Amasawa et al., 2020; Адактилос, Чаус, Молдован, 2018], что позволяет более эффективно использовать ресурсы и сократить отходы и выбросы, в частности выбросы парниковых газов [Amasawa et al., 2020].

В странах с развитой шеринговой экономикой (США, Германия) исследователи уделяют большое внимание поведению пользователей соответствующих сервисов. Выявлено, что на отношение потребителей к аренде вещей влияет множество факторов [Lawson et al., 2016; Becker-Leifhold, 2018], значительно различающихся в зависимости от культурных особенностей людей [Irana, Geiger, Schrader, 2018].

Для отечественной науки изучение шеринга вещей - относительно новая тема, ее комплексные исследования практически отсутствуют. Следует признать, что степень научной разработанности проблематики направлений развития и мотивации пользователей шеринга вещей не соответствуют интенсивности его роста.

Целью данного исследования выступает установление приоритетов пользователей и выявление потребительских тенденций на рынке шеринга вещей в России.

Основные задачи исследования:

1) определить уровень и структуру интереса интернет-пользователей к шерингу вещей;

2) исследовать характер и динамику наиболее популярных запросов пользователей;

3) оценить степень развитости рынка шеринга вещей;

4) выявить причины и ограничения развития шеринга вещей с позиции потребителя.

Мы будем выявлять предпочтения пользователей шеринга вещей на основе их запросов в интернете, а степень развития рынка шеринга вещей - на основании данных о посещаемости и дате создания сайтов шеринговых компаний.

\section{Этапы и методы исследования}

Популярность поисковых запросов интернет-пользователей часто рассматривается в качестве показателя, определяющего характеристики экономических процессов.

\footnotetext{
1 Подробнее см.: Объем бытовых услуг населению (оперативные данные) с 2017 г. //ЕМИСС. Государственная статистика. URL: https://fedstat.ru/indicator/57792 (дата обращения: 20.05.2020).

2 P2P-peer-to-peer или person-to-person.

з Подробнее см.: Экономика совместного потребления в России //TIARCENTER. 2020. 10 марта. URL: https://tiarcenter. com/sharing-report-2019/ (дата обращения: 01.04.2021).
} 
Популярность поисковых запросов используют, например, при исследовании туристских потоков [Charalampopoulos, Nastos, Didaskalou, 2017], уровня безработицы [Simionescu, Zimmermann, 2017], трудовой миграции [Веремчук, Розбицький, 2019], криптовалюты [Kristoufek, 2013], прогнозирования макроэкономических переменных [Борочкин, 2013].

Если количественно оценить связь между информационными запросами людей и их поведением, то можно спрогнозировать будущее значение экономических переменных, например, чистый ввоз/вывоз капитала частным сектором, общий уровень безработицы и т.д., еще до того момента, как органы государственной статистики зарегистрируют сделки по покупке каких-либо товаров, денежные переводы за границу или заключение трудовых договоров [там же].

Наиболее удобным инструментом изучения поисковых запросов интернетпользователей считается сервис Google Trends (https://trends.google.com), показывающий степень популярности определенных ключевых слов в Google на множестве языков в разных регионах планеты. Данные о популярности поисковых запросов позволяют в реальном времени исследовать широкий спектр социальноэкономических тенденций во всем мире и могут быть использованы для выработки своевременных, обоснованных и эффективных решений на благо общества [Askitas, 2015].

Плюсы анализа поисковых запросов с помощью Google Trends:

1) Данные поисковой активности позволяют определить наиболее устойчивые популярные запросы пользователей и получить широкий спектр информации о них [Askitas, 2015: 1].

2) Данные постоянно обновляются и доступны в режиме реального времени, благодаря чему можно быстро выявлять критические тенденции [Askitas, 2015: 1; Соколов, 2018:3].

В качестве минусов метода анализа поисковых запросов Google Trends H. Acкитас выделяет следующие его характеристики [Askitas, 2015: 1]:

1) Данные являются собственностью компании Google и доступны только в обобщенном виде.

2) Методология поставляется без контроля версий и описана недостаточно подробно, что затрудняет анализ данных.

3) Географическое распределение данных о поисковых запросах может быть неточным из-за ошибок в определении расположения IP-адресов.

4) Значение ключевого слова может изменяться во времени и в разных регионах, что снижает пригодность данных для анализа.

5) Рейтинг страниц (page rank) поисковой системы Google меняется с течением времени, что может исказить данные, как и различные формы цензуры.

Чу Х. и Вариан Х. добавляют еще один недостаток [Choi, Varian, 2012: 3]:

6) Отчетные показатели Google Trends вычисляются с использованием метода выборки каждый раз заново, и поэтому результаты могут незначительно меняться изо дня в день.

Несмотря на имеющиеся минусы, анализ поисковых запросов с помощью Google Trends улучшает модели прогнозирования экономических переменных [Woo, Owen, 2019]. 
Использование анализа поисковых запросов с помощью Google Trends особенно актуально для исследования тех социально-экономических сфер, где ситуация быстро меняется, поскольку большинство экономических переменных публикуются с запозданием, что затрудняет точную оценку текущей ситуации. К таким сферам, например, относится шеринговая экономика и, в частности, шеринг вещей.

Наше исследование проводилось в мае 2020 г. Для решения второй и третьей задач исследования мы использовали инструменты Google Trends и "Яндекс. Подбор слов". На первом этапе работы были собраны статистические данные Google Trends o поисковых запросах, исходящих с территории России за десять лет: с мая 2010 г.по май 2020 г. Мы определили 25 самых популярных ("топ») и столько же наиболее быстро набирающих популярность ("в тренде») поисковых запросов, связанных со словами "аренда" и "прокат». Затем мы собрали и проанализировали статистические данные по каждому из этих запросов (за исключением аренды недвижимости и автотранспорта $\left.{ }^{4}\right)$.

На втором этапе нами были проанализированы запросы, связанные со словами "аренда" и "прокат", собранные с помощью поискового инструмента "Яндекс. Подбор слов" (https://wordstat.yandex.ru), который показывает количество запросов, включающих заданное слово или словосочетание, по всем регионам России за месяц на определенную дату (в нашем случае - на 19 мая 2020 г. ${ }^{5}$ ). Отсутствие в исследовании данных о поисковых запросах, содержащих слова "аренда" и "прокат", в другие периоды времени объясняется спецификой инструмента "Яндекс. Подбор слов". Дело в том, что он не предоставляет возможности определения рейтинга запросов по количеству показов в месяц в различные периоды времени. Тем не менее "Яндекс. Подбор слов" дает более глубокий срез поисковых запросов, нежели Google Trends.

Для решения третьей задачи исследования нами были проанализированы данные о создании и посещаемости наиболее популярных сайтов, предоставляющих услуги по аренде вещей. К таким ресурсам мы отнесли те, что находятся в топ-10 поиска Google по запросам «аренда", "прокат" и связанным с ними тегам - «топ» и "в тренде". На третьем этапе исследования мы собрали сведения о дате создания таких сайтов. В качестве источника данных об их регистрации использовался сервис Whois компании Ru-Center - одного из крупнейших в России регистраторов доменных имен и хостинг-провайдеров ${ }^{6}$. Мы не включили в выборку сайты, для которых аренда вещей не выступает основным направлением деятельности, а именно: интернет-сервисы для размещения объявлений о продаже товаров (например, Avito), сайты государственных органов власти (например, официальный сайт мэра и правительства Москвы), справочных систем (например, «Википедия») и розничных компаний.

На четвертом этапе мы собрали и изучили сведения о посещаемости отобранных сайтов. Материалом для анализа стали соответствующие данные компаний

\footnotetext{
4 Запросы по аренде недвижимости и автотранспорта не рассматривались, поскольку темой нашего исследования выступают предпочтения пользователей сервисов совместного пользования (шеринга) вещей.

5 Дата была выбрана произвольно.

6 Подробнее о сервисе Whois cм.: URL: https://www.nic.ru/whois (дата обращения: 19.05.2020).
} 
SimilarWeb ${ }^{7}$ и $2 \mathrm{IP}^{8}$ за апрель ${ }^{9} 2020$ г. Выбор этих интернет-сервисов обусловлен тем, что они предоставляют услуги по веб-аналитике, пользуются популярностью у исследователей и дают свободный доступ к данным.

Наконец, для выявления причин и ограничений развития шеринга вещей с позиции потребителя (первая задача исследования) мы провели анализ и обобщили результаты проектов, реализованных “ТИАР-Центром" и Российской ассоциацией электронных коммуникаций (РАЭК) ${ }^{10}$, а также журналом «Эксперт» ${ }^{11}$.

\section{Результаты исследования}

Быстрое развитие рынка шеринга вещей связано с рядом преимуществ, получаемых пользователями и владельцами имущества. Работы, посвященные изучению этих преимуществ, как и факторов, сдерживающих развитие шеринга, в отечественной социальной науке практически отсутствуют. Данная тема затрагивалась, пожалуй, только в исследованиях шеринговой экономики, выполненных "ТИАР-Центром" и Российской ассоциацией электронных коммуникаций (РАЭК), а также в серии интервью, проведенных журналом "Эксперт" с представителями шеринговых компаний.

Согласно выводам “ТИАР-Центра" и РАЭК, пользователи шеринговых сервисов предпочитают арендовать вещи, а не покупать их по следующим причинам ${ }^{12}$ :

1) Возможность сэкономить - если ожидается, что вещь будет использоваться очень редко.

2) Возможность воспользоваться вещью здесь и сейчас, а не копить средства на ее приобретение в течение долгого времени.

3) Возможность протестировать вещь перед покупкой.

Согласно выводам ${ }^{13}$, полученным в ходе анализа интервью с представителями шеринговых компаний, основными мотивами их клиентов, помимо желания сэкономить, оказываются потребность в повышении качества жизни и социальная ответственность. Часто пользователи предпочитают арендовать более качественные товары, чем покупать дешевые.

Шеринг вещей дает преимущества не только их пользователям, но и обществу в целом благодаря более эффективному использованию ресурсов и сокращению объемов отходов и вредных выбросов. Преимущества шеринга вещей перечислены на рисунке 1.

\footnotetext{
7 Подробнее об инструменте см.: URL: https://www.similarweb.com/top-websites (дата обращения: 19.05.2020).

8 Подробнее об инструменте cм.: URL: https://2ip.ru/site-statistics (дата обращения: 19.05.2020).

9 Указанные сервисы предоставляют данные о посещаемости за предыдущий месяц, возможность выбрать необходимый период отсутствует.

10 Экономика совместного потребления в России //TIARCENTER. 2018. 21 ноября. URL: https://tiarcenter.com/sharingeconomy-research (дата обращения: 01.04.2021); Экономика совместного потребления в России //TIARCENTER. 2020. 10 марта. URL: https://tiarcenter.com/sharing-report-2019 (дата обращения: 01.04.2021).

${ }^{11}$ Инкижинова С. Бедным хочется купить, обеспеченным - получить удовольствие //Эксперт. 2020. 16 мapта. URL: https://expert.ru/expert/2020/12/bednyim-hochetsya-kupit-obespechennyim--poluchit-udovolstvie/ (дата обращения: 21.03.2021).

12 Экономика совместного потребления в России 2018: модели, отрасли, тренды //TIARCENTER. PAЭK. 2018. URL: https://raec.ru/upload/files/raec-sharing-economy-nov2018.pdf (дата обращения: 20.05.2020).

${ }^{13}$ Там же.
} 
ПОЛЬЗОВАТЕАИ - Возможность сэкономить при условии,
что аренда вещи обойдется дешевле, чем
покупка новой.

- Возможность пользоваться премиальным товаром или предметом роскоши по приемлемой цене.

- Возможность воспользоваться вещью здесь и сейчас, а не копить в течение долгого времени.

- Возможность протестировать вещь переА покупкой.

- Отсутствие необходимости в поддержании вещи в товарном состоянии.

- Отсутствие рисков утраты или повреждения вещи при хранении.

- Экономия пространства, поскольку нет необходимости в хранении редко используемой вещи.

- Отсутствие затрат на хранение.
В/ААЕЛЬЦЫ

Возможность получить Аоход За счет сАачи имущества в аренду

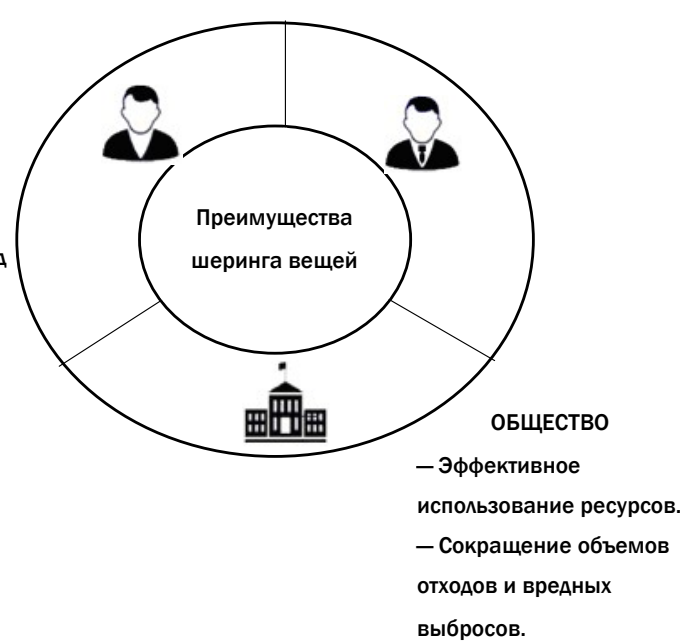

Среди факторов, препятствующих развитию шеринга вещей (см. рис. 2), можно выделить следующие:

1) Стоимость аренды, которая вызывает заинтересованность потребителя, если ее цена составляет $10 \%-20 \%$ розничной стоимости продукта (что бывает нечасто). Если вещь предлагается арендовать за треть ее розничной цены и более, то пользователи не видят в этом смысла.

2) Трудности с доставкой и большие временнь́е затраты на поиск и получение товара ${ }^{14}$.

3) Недостаточная осведомленность пользователей о подобных сервисах, опасения владельцев, что арендаторы испортят сдаваемые им вещи, страх арендаторов повредить чужое имущество ${ }^{15}$.

Определим далее предпочтения российских пользователей сервисов шеринга вещей с помощью оценки уровня и анализа структуры их интереса к отдельным категориям товаров. Рассмотрим, как менялся интерес пользователей к шерингу вещей, на основе статистики поисковых запросов Google Trends, исходящих с территории России, за десять лет: с мая 2010 г. по май 2020 г. На трех графиках (см. рис. 3-5) представлены запросы, сгруппированные по категориям вещей: одежда, спорттовары, инструменты и оборудование. Числа обозначают уровень интереса к теме по отношению к наиболее высокому показателю в таблице для определен-

\footnotetext{
14 Там же.

15 Там же.
} 
ного периода времени. Наивысший уровень популярности запроса обозначен ста баллами, вдвое меньший уровень популярности запроса - пятидесятью.

Рис. 2. Факторы, сдерживающие развитие шеринга вещей

ПОЛЬЗОВАТЕАИ

- Низкая осведомленность о шеринге вещей.

- Риск повреждения арендуемого имущества.

- Аороговизна аренды.

- Высокие затраты времени на поиск и получение вещи.

- Высокая стоимость Аоставки.

- Отсутствие удобных вариантов Аоставки.

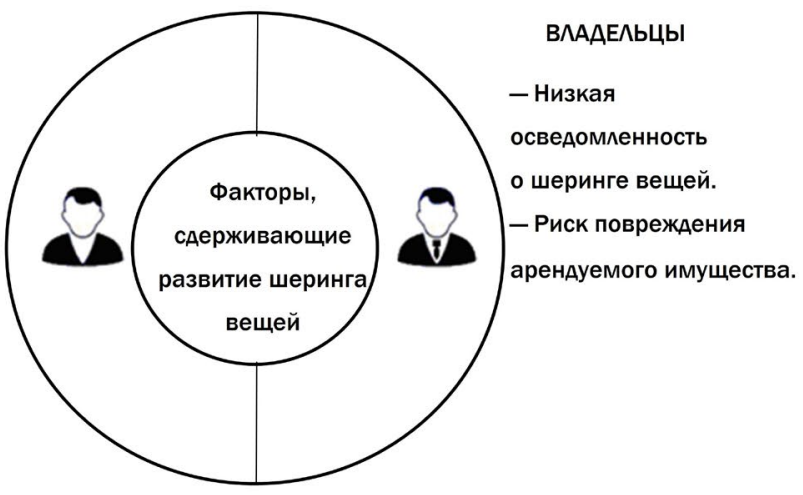

Рис. З. График скользящих средних для популярности поисковых запросов, сгруппированных по категории “одежда"

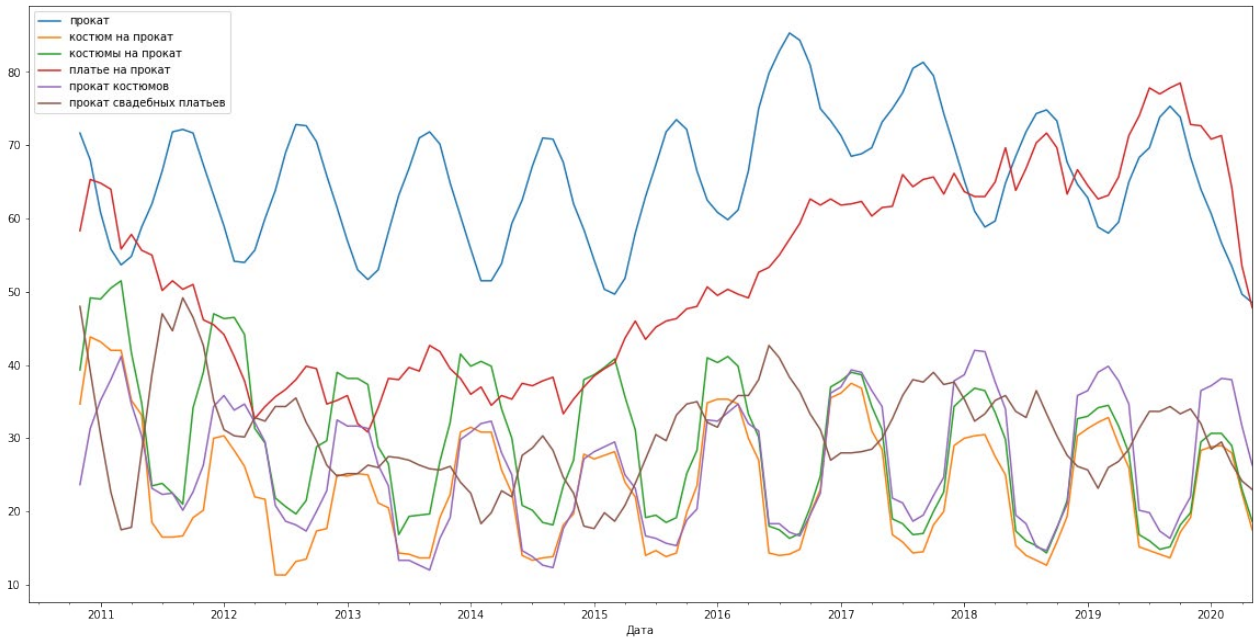

Из рисунка 3 видно, что в 2015-2016 гг. выросла популярность запроса «прокат", но затем этот тренд пошел на снижение. Популярность запросов "прокат свадебных платьев", "костюм на прокат", "прокат костюмов" стабильна на протяжении последних десяти лет. Популярность запроса "платье на прокат" с 2016 г. демонстрирует позитивную динамику. В начале 2020 г. произошло падение интереса пользователей к прокату одежды, вызванное, по-видимому, пандемией COVID-19 и связанными с ней карантинными ограничениями. 
Рис. 4. График скользящих средних для популярности поисковых запросов, сгруппированных по категории “спорттовары"

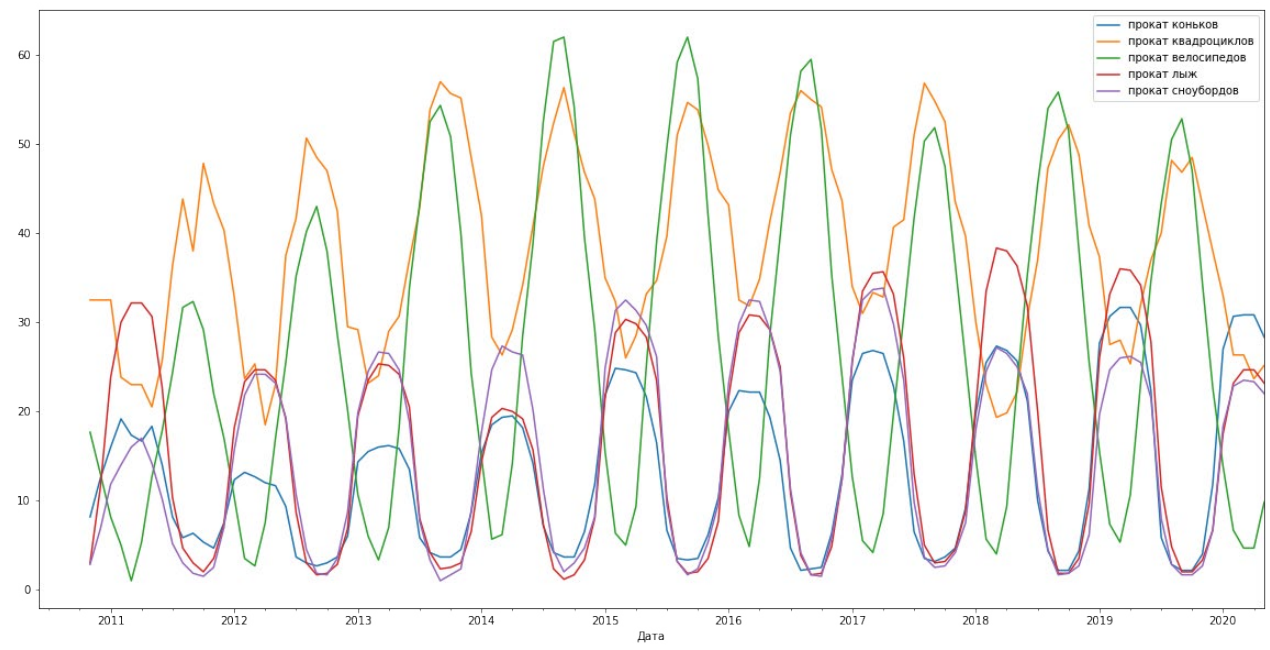

Анализируя данные, представленные на рисунке 4, можно отметить, что количество запросов "прокат велосипедов" росло вплоть до 2015 г., «прокат квадроциклов" - до 2016 г., «прокат сноубордов" - до 2017 г., "прокат лыж» — до 2018 г. Затем тренд сменился на отрицательный. Популярность запроса "прокат коньков" с 2014 г. увеличивается (стабильно позитивный тренд).

Рис. 5. График скользящих средних для популярности поисковых запросов, сгруппированных по категории “инструменты и оборудование"

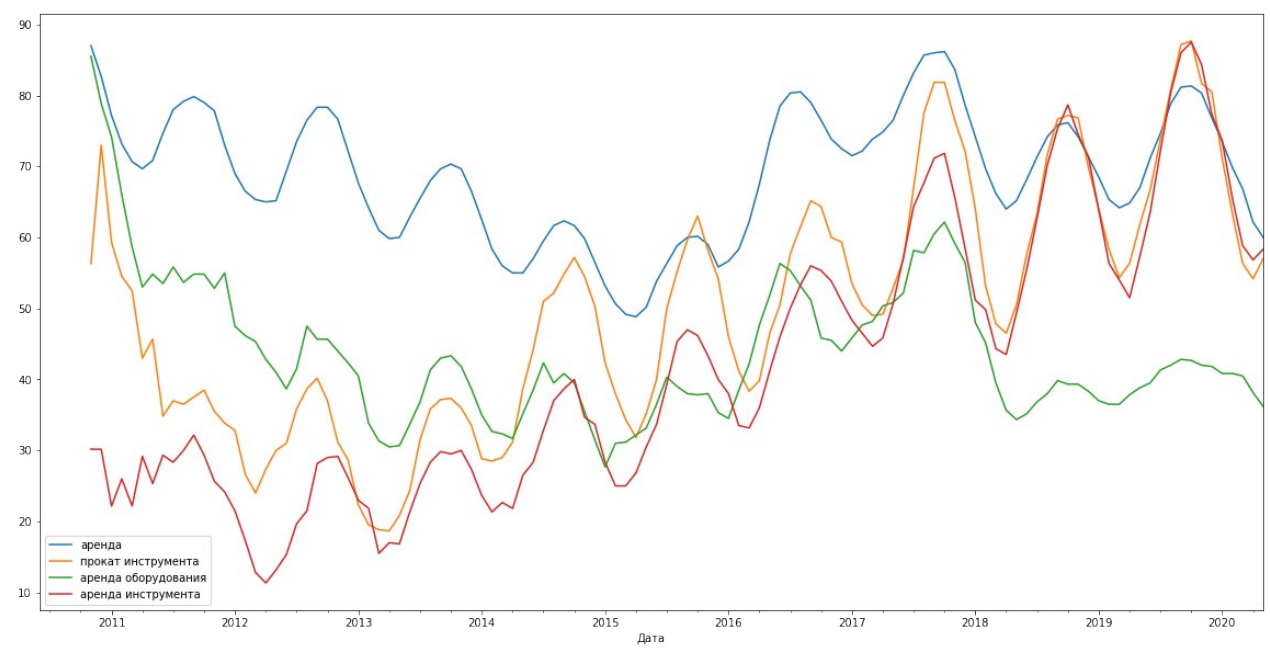


Из рисунка 5 видно, что в 2016-2017 гг. произошло увеличение популярности запроса "аренда", затем этот тренд пошел на снижение. У популярности запросов "прокат инструмента" и «аренда инструмента" с 2014 г. сохраняется позитивный тренд.

Причины снижения числа поисковых запросов "аренда", "прокат", "прокат велосипедов", "прокат сноубордов", "прокат лыж" могут быть различными. Мы предполагаем, что одним из возможных факторов оказывается сокращение группы новых или нерегулярных пользователей, которые вводят в строку поиска высокочастотные запросы, попадающие в топ. В отличие от них постоянные клиенты шеринговых сервисов делают низкочастотные запросы или используют приложение. Так, приложение “Велобайк" (городской велопрокат г. Москвы) было скачано в GooglePlay более 500000 раз, URent (прокат велосипедов на юге России и самокатов в различных городах) - тоже более 500000 раз, LuckyBike (прокат велосипедов в Адлере, Белгороде, Владимире, Екатеринбурге и других городах России) - более 100000 раз, SmartBike (прокат велосипедов в СанктПетербурге) - более 50000 раз $^{16}$.

Еще одной возможной причиной может быть то, что пользователи сокращают аренду товаров, без которых можно обойтись (например, квадроциклов и сноубордов) из-за снижения реальных доходов.

Увеличение количества запросов, связанных с арендой платьев, инструмента и оборудования, также может быть связано со снижением реальных доходов, поскольку пользователи все больше предпочитают арендовать, а не покупать товары, без которых трудно обойтись (инструменты, одежда).

Таким образом, для прояснения причин снижения популярности некоторых поисковых запросов (например, "прокат велосипедов", "прокат квадроциклов", "прокат сноубордов", "прокат лыж») требуются дальнейшие исследования.

Интерес пользователей, согласно популярным запросам, связанным с шерингом вещей, изменяется сезонно. Наиболее ярко проявляется сезонность у запросов, относящихся к прокату спортивных товаров (например, "прокат лыж»). Исходя из этого, сервисам шеринга вещей необходимо учитывать сезонность при формировании своего ассортимента. На рисунке 6 представлен график зависимости значений коэффициентов автокорреляции от величины лага для популярности запроса «прокат велосипедов" ${ }^{17}$. На оси Ү отложены коэффициенты автокорреляции и доверительные интервалы, на оси X-величина лага.

Итак, анализ значений автокорреляционной функции (см. рис. 6) позволяет сделать вывод о наличии во временном ряде линейной тенденции и сезонных колебаний периодичностью в 12 месяцев.

На втором этапе исследования, используя сервис "яндекс. Подбор слов", мы определяли уровень и структуру интереса пользователей к шерингу вещей. Данный инструмент демонстрирует количество показов в месяц, которое можно получить,

\footnotetext{
16 Данные собраны автором в Google Play: URL: https://play.google.com (дата обращения: 20.04.2021).

17 В ходе исследования для всех наиболее популярных запросов со словами «аренда»/ прокат" были построены коррелограммы и проведена оценка значимости коэффициентов автокорреляции. Выявлено, что наиболее ярко выражена сезонность у запросов, связанных с прокатом спортивных товаров, например, «прокат лыж», “прокат велосипедов". Чтобы не перегружать статью, в ней приведен лишь один график автокорреляции.
} 
выбрав определенные запросы в качестве ключевой фразы. Нас интересовали наиболее популярные поисковые запросы со словами "аренда" или "прокат" по России в целом за месяц на дату 19 мая 2020 г. В результате мы выявили наиболее востребованные пользователями товары.

Рис. 6. Коррелограмма популярности запроса "прокат велосипедов"

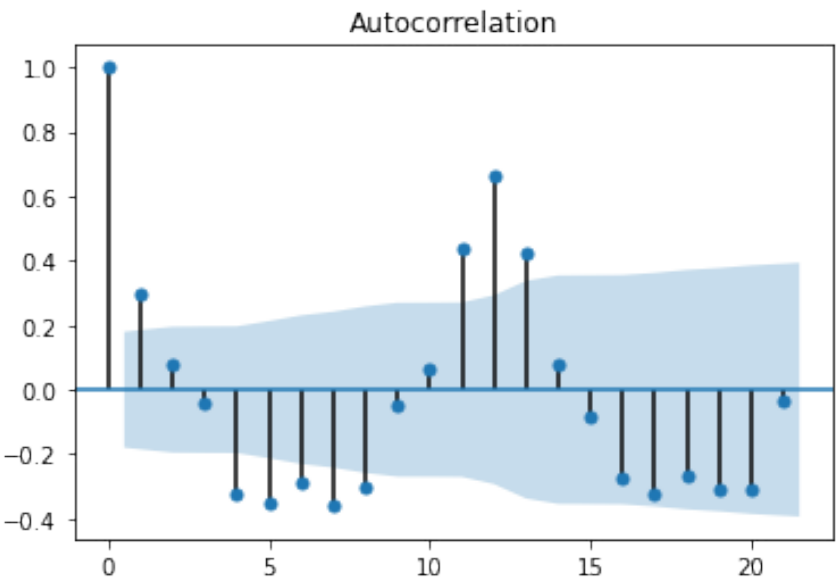

Как видно из таблицы 1, первое место по количеству поисковых запросов занимают средства передвижения (велосипеды, самокаты, электросамокаты, квадроциклы и др.). На втором месте по популярности находятся инструменты и оборудование. На третьем месте - одежда.

Таблица 1. Количество показов за месяц по наименованиям товаров

\begin{tabular}{|l|c|}
\hline Наименование товаров в сочетании со словами “аренда” или “прокат” & $\begin{array}{c}\text { Количество } \\
\text { показов в месяц }\end{array}$ \\
\hline Велосипеды, самокаты, квадроциклы и др. & 170956 \\
\hline $\begin{array}{l}\text { Инструменты и оборудование (перфораторы, пилы, генераторы, лестницы } \\
\text { и др.) }\end{array}$ & 139484 \\
\hline Одежда (костюмы, платья, в т. ч. свадебные и др.) & 81933 \\
\hline Мебель (столы, кресла и др.) & 25994 \\
\hline Садовая техника (мотоблоки, культиваторы и др.) & 25423 \\
\hline Спортповары (тренажеры, беговые дорожки и др.) & 22784 \\
\hline Бытовая техника (холодильники, пылесосы и др.) & 18589 \\
\hline Часы & 18518 \\
\hline Компьютерная техника (компьютеры, ноутбуки, принтеры и др.) & 17932 \\
\hline Кальяны & 16741 \\
\hline Фототехника (фотокамеры и др.) & 13773 \\
\hline Игры и приставки & 13511 \\
\hline Детские товары (коляски, игрушки и др.) & 10394 \\
\hline Палатки & 7421 \\
\hline
\end{tabular}




\begin{tabular}{|l|c|}
\hline Наименование товаров в сочетании со словами “аренда» или “прокат” & $\begin{array}{c}\text { Количество } \\
\text { показов в месяц }\end{array}$ \\
\hline Металлоискатели & 6346 \\
\hline Мангалы & 5340 \\
\hline Биотуалеты & 4482 \\
\hline Костыли & 3702 \\
\hline Весы & 3428 \\
\hline
\end{tabular}

На основе полученных данных можно сделать вывод, что значительную долю в потребительском спросе занимают вещи, которые будут использоваться ситуативно (костюмы, часы, платья). Заметная часть также приходится на товары, которые применяются сезонно (велосипеды, мангалы) или разово (мотоблоки, перфораторы, фототехника, игровые приставки), или в период поездки (палатки, биотуалеты, коляски).

Далее оценим динамику интереса российских пользователей сервисов шеринга вещей с помощью анализа посещаемости и даты создания сайтов компаний, оказывающих услуги по шерингу вещей.

Результатом третьего этапа исследования стало определение и анализ периода регистрации самых посещаемых сайтов, предоставляющих услуги по шерингу вещей. В качестве наиболее популярных сайтов были выбраны те, которые находятся в топ-10 поиска Google по запросам "аренда" и "прокат". Поскольку на рейтинг сайта в поисковой выдаче Google влияет известность компании, можно предположить, что компании из топ-10 входят в число лидеров на рынке шеринга вещей. Источником данных о регистрации сайта выступил сервис Whois компании RU-CENTER (AO «Региональный Сетевой Информационный Центр») ${ }^{18}$. Гистограмма распределения числа сайтов по дате их регистрации представлена на рисунке 7 .

Рис 7. Гистограмма распределения числа сайтов по дате их регистрации в России за период 1996-2021 гг.

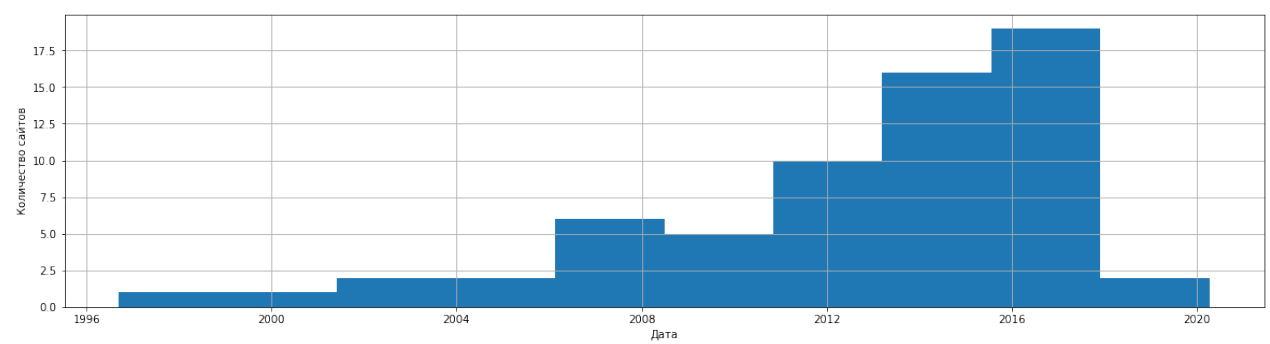

Подавляющее большинство сайтов из топ-10 Google по самым популярным запросам, связанным с шерингом вещей, было создано в период с 2012 по 2017 г. Более трети компаний-молодые, их сайты появились менее десяти лет назад. Пик регистрации приходится на 2016-2017 гг. Таким образом, можно сделать

\footnotetext{
$\overline{18}$ Подробнее о сервисе Whois cм.: URL: https://www.nic.ru/whois (дата обращения: 19.05.2020).
} 
вывод, что лидерами на рынке шеринга вещей являются молодые компании, созданные в последние 10-15 лет.

Четвертый этап нашего исследования включал анализ посещаемости сайтов, предоставляющих услуги по аренде вещей, за апрель 2020 г. Источниками данных выступили интернет-сервисы компаний SimilarWeb ${ }^{19}$ и 2IP ${ }^{20}$, занимающихся вебаналитикой (см. рис. 8).

Рис. 8. Гистограмма распределения числа сайтов по количеству визитов их посетителей

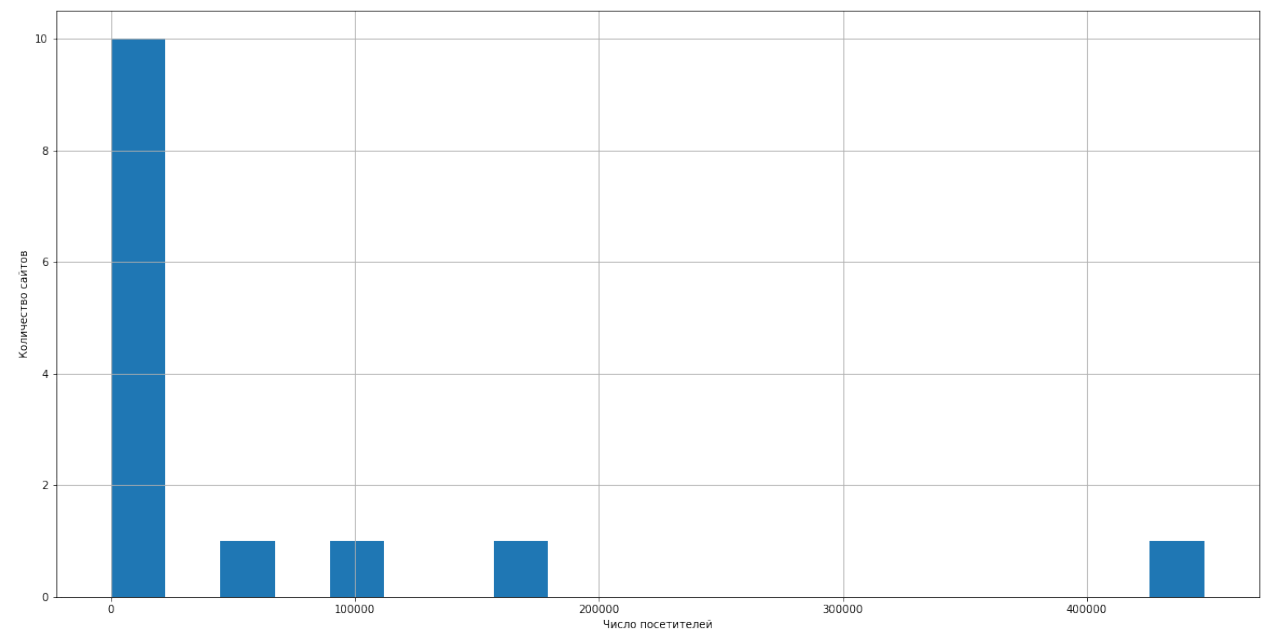

Как видно из рисунка 8, посещаемость подавляющего большинства сайтов, входящих в топ-10 Google по запросам, связанным с шерингом вещей, не превышает 100 тыс. визитов в месяц. Таким образом, популярность интернет-сервисов по шерингу вещей невелика и сильно отстает от посещаемости сайтов торговых компаний. Для сравнения нами были выбраны интернет-магазины, предлагающие аналогичные товары, с доступной статистикой посещений. Источниками данных выступили уже упоминаемые выше сервисы компаний SimilarWeb и 2IP. Как показал наш анализ, в апреле 2020 г. посещаемость сайтов "Все инструменты" (https:// www.vseinstrumenti.ru) и "Петрович" (https://petrovich.ru), которые продают строительные материалы и инструменты, а также оказывают услуги по аренде последних, составила 16,4 млн и 4,0 млн визитов соответственно. Это в десятки раз больше, чем посещаемость сайтов компаний, сдающих инструменты в аренду. Количество визитов на сайты «Квадро Экстрим» (https://kvadro-extrim.ru/) и Pro-kvad (https:// pro-kvad.ru/), предлагающие квадроциклы в аренду, не превышает 500 в месяц. Это в разы меньше, чем у магазинов по продаже квадроциклов, например, у ATV4x4 (http://www.atv4x4.ru/) и Stels (https://stelsbicycle.ru/). Популярность компаний по аренде велосипедов - например, Kruti-Pedali (https://www.kruti-

\footnotetext{
19 Подробнее см.: URL: https://www.similarweb.com/top-websites (дата обращения: 19.05.2020).

20 Подробнее см.: URL: https://2ip.ru/site-statistics (дата обращения: 19.05.2020).
} 
pedali.ru/) и "Оливер Байкс" (https://bikerentalmoscow.com/),一ниже, чем у сайтов крупных магазинов по продаже велосипедов - например, "ВелоСтрана» (https:// www.velostrana.ru/) и "ВелоСклад" (https://www.velosklad.ru/).

Итак, проведенное исследование подтверждает активное развитие рынка шеринга вещей: количество соответствующих запросов возрастает. Несмотря на то, что структура интереса к тем или иным товарам напрокат подвержена сезонным колебаниям, в целом этот интерес демонстрирует возрастающий тренд; появляется все больше компаний, предлагающих услуги шеринга вещей.

\section{Заключение}

Российские потребители постепенно осознают преимущества шеринга вещей и склоняются к их использованию вместо владения ими. Это происходит потому, что в перечень преимуществ шеринга входят следующие возможности: сэкономить; воспользоваться премиальным товаром или предметом роскоши по приемлемой цене; получить вещь здесь и сейчас, а не копить деньги; протестировать вещь перед покупкой; не нести затраты на поддержание вещи в товарном состоянии и ее хранение; не нести риски утраты или повреждения вещи в период неиспользования; сэкономить пространство в жилище или гараже.

Основными препятствиями для развития шеринга вещей оказываются: высокая стоимость аренды; невысокая осведомленность потребителей о ее преимуществах; трудности с доставкой; большие затраты времени на поиск и получение вещи; возможные риски повреждения арендуемых товаров.

Наиболее востребованные на российском рынке шеринга средства передвижения - велосипеды, самокаты, квадроциклы и др. Следующие по популярности - товары, используемые потребителями ситуативно (костюмы, часы, платья). Замыкают список наиболее востребованных вещи, потребность в которых имеет ярко выраженную сезонность (например, мангалы), а также те, которые будут применяться разово (например, мотоблоки, перфораторы, фототехника, игровые приставки) или в период поездки (палатки, биотуалеты, коляски).

Структура спроса у пользователей шеринга вещей неоднородна. На некоторые товары (например, костюмы) сохраняется стабильный спрос. Быстрый рост интереса к отдельным категориям вещей (например, квадроциклам и сноубордам) в последние два-пять лет сменился снижением. Популярность ряда других товарных групп (например, инструментов) растет. Поскольку спрос на наиболее востребованные товары имеет выраженную годовую сезонность, сервисы шеринга вещей должны учитывать этот факт при формировании ассортимента товаров.

Лидерами на рынке шеринга вещей выступают молодые компании, созданные преимущественно в период с 2012 по 2017 г. Посещаемость сайтов, предоставляющих товары в аренду, невелика и сильно отстает от посещаемости сайтов торговых компаний. Объем рынка аренды вещей незначителен, однако быстро расширяется.

\section{Список литературы (References)}

Адактилос А.Д., Чаус М. С., Молдован А. А. Шеринговая экономика // Economics. 2018. № 4. С. 95-100. 
Adaktilos A. D., Chaus M. S., Moldovan A. A. (2018) Schering Economics. Economics. No. 4. P. 95-100. (In Russ.)

Борочкин А. А. Использование статистики поисковых запросов в сети Интернет для краткосрочного прогнозирования макроэкономических переменных // Деньги и кредит. 2013. № 8. С. $28-32$.

Borochkin A. A. (2013) Using the Statistics of Search Queries on the Internet for ShortTerm Forecasting of Macroeconomic Variables. Money and Credit. No. 8. P. 28-32.

Веремчук А. В., Розбицький М. А. Оцінка потенціалу “великих даних" для дослідження трудової міграції // Демографія та соціальна економіка. 2019. № 1. С. 197 208. https://doi.org/10.15407/dse2019.01.196.

Veremchuk A. V., Rozbitsky M. A. (2019) Estimation of Big Data in Labor Migration Research. Demography and Social Economy. No. 1. P. 197-208. https://doi.org/ 10.15407/dse2019.01.196. (In Ukr.)

Земскова Е. С. Шеринг как отражение ценностных ориентиров потребителя в цифровой экономике //Экономика и экологический менеджмент. 2019. № 3. C. $17-27$.

Zemskova E.S. (2019) Sharing as the Reflection of Consumer Values in Digital Economy. Economics and Environmental Management. No. 3. P. 17-27. (In Russ.)

Маркеева А. В. Экономика участия (sharing economy): проблемы и перспективы развития // Инновации. 2017. № 8. С. 73-80.

Markeeva A. V. (2017) The Economy of Participation (Sharing Economy): Problems and Development Prospects. Innovations. No. 8. P. 73-80. (In Russ.)

Соколов С. В. Применение веб-аналитического инструментария Google Trends в социогуманитарных и библиотековедческих исследованиях // Библиосфера. 2018. № 4. C. 3-9.

Sokolov S. V. (2018) The Use of Web-Analytical Tools Google Trends in Socio-Humanitarian and Library Research. Bibliosphere. No. 4. P. 3-9. (In Russ.) https://doi.org/ 10.20913/1815-3186-2018-4-3-9

Amasawa E., Shibata T., Sugiyama H., Hirao M. (2020) Environmental Potential of Reusing, Renting, and Sharing Consumer Products: Systematic Analysis Approach. Journal of Cleaner Production. Vol. 242. https://doi.org/10.1016/j.jclepro. 2019.118487.

Askitas N. (2015) Google Search Activity Data and Breaking Trends. IZA World of Labor. No. 206. https://doi.org/10.15185/izawol.206.

Becker-Leifhold C. V. (2018) The Role of Values in Collaborative Fashion Consumption A Critical Investigation Through the Lenses of the Theory of Planned Behavior. Journal of Cleaner Production. Vol. 199. P. 781-791. https://doi.org/10.1016/j. jclepro.2018.06.296.

Belk R. (2014) You Are What You Can Access: Sharing and Collaborative Consumption Online. Journal of Business Research. Vol. 67. No. 8. P. 1595-1600. https://doi. org/10.1016/j.jbusres.2013.10.001. 
Botsman R., Rogers R. (2010) What's Mine Is Yours: The Rise of Collaborative Consumption. New York: Harper Collins Publishers.

Charalampopoulos I., Nastos P., Didaskalou E. (2017) Human Thermal Conditions and North Europeans' Web Searching Behavior (Google Trends) on Mediterranean Touristic Destinations. Urban Science. Vol. 1. No. 8. https://doi.org/10.3390/ urbansci1010008.

Choi H., Varian, H. (2012) Predicting the Present with Google Trends. Economic Record. Vol. 88. No. s1. P. 2-9. https://doi.org/10.1111/j.1475-4932.2012.00809.x.

Frenken K. (2017) Political Economies and Environmental Futures for the Sharing Economy. Philosophical Transactions of the Royal Society A. Vol. 375. No. 2095. https://doi.org/10.1098/rsta.2016.0367.

Irana S., Geiger S., Schrader U. (2018) Collaborative Fashion Consumption - A CrossCultural Study between Tehran and Berlin. Journal of Cleaner Production. Vol. 212. P. 313-323. https://doi.org/10.1016/j.jclepro.2018.11.163.

Kristoufek L. (2013) Bitcoin Meets Google Trends and Wikipedia: Quantifying the Relationship between Phenomena of the Internet Era. Scientific Reports. No. 3. https:// doi.org/10.1038/srep03415.

Lawson S. J., Gleim M.R., Perren R., Hwang J. (2016) Freedom from Ownership: An Exploration of Access-Based Consumption. Journal of Business Research. Vol. 69. No. 8. P. 2615-2623. https://doi.org/10.1016/j.jbusres.2016.04.021.

Simionescu M., Zimmermann K. F. (2017) Big Data and Unemployment Analysis. GLO Discussion Paper. No. 81. URL: https://EconPapers.repec.org/RePEc:zbw:glodps:81 (дата обращения: 04.08.2021).

Tukker A. (2015) Product Services for a Resource-Efficient and Circular Economy A Review. Journal of Cleaner Production. Vol. 97. P. 76-91. https://doi.org/10.1016/ j.jclepro.2013.11.049.

Woo J., Owen A. L. (2019) Forecasting Private Consumption with Google Trends Data. Journal of Forecasting. Vol. 38. No. 2. P. 81-91. https://doi.org/10.1002/for.2559. 